A 19-year-old male presented with complaints of acute onset abnormal, episodic intermittent involuntary jerky movement of all four limbs, trunk and eye lids without loss of consciousness from 12 days. These movements used to subside during sleep and not exacerbated by visual, auditory or tactile stimulus. There was positive history of difficulty in walking with swaying on either side and slurring of speech from last 10 days. On general examination he had gum hypertrophy [Figure 1] but no evidence of skin rash. Neurological examination revealed abnormal chaotic multidirectional movement of eyes suggestive of opsoclonus with evidence of myoclonic jerks involving all four limbs, face and eyelids [Videos 1 and 2]. He had severe trunk as well as gait ataxia, incoordination and dysmetria. Rest of neurological examination was normal.

He had past history of tuberculous meningitis, hydrocephalus, and generalized tonic clonic seizures since the age of two and half years. He was treated with complete course of antitubercular therapy along with ventriculo-peritoneal shunt for hydrocephalus. His phenytoin dose was increased from 300 to $500 \mathrm{mg} / \mathrm{d}$ 1 month back due to one episode of GTCS and Tab Levetiracetam $500 \mathrm{mg}$ BD was added recently for myoclonic jerks but there was no improvement in his symptoms. A clinical diagnosis of OMS with ataxia (gait, truncal as well as appendicular) was considered.

Hematological, biochemical and cerebro spinal fluid examinations were normal. CSF was negative for Herpes simplex virus (HSV), Japanese encephalitis, measles and varicella zoster as well as Cryptococcus neoformas, and Mycobacterium tuberculosis. The immunological study for Dengue, rubella, HIV, Mycoplasma

\title{
Opsoclonus - Myoclonus syndrome induced by phenytoin intoxication
}

Sir,

Phenytoin is an antiepileptic drug that continues to be used widely for treatment of focal and generalized tonic-clonic seizures. Phenytoin has narrow therapeutic window. Therefore, even a minor increase in dose leads to toxicity. Opsoclonus and myoclonus both are adverse effect of phenytoin ${ }^{[1]}$ but opsoclonusmyoclonus syndrome (OMS) as a consequent effect of phenytoin toxicity is not previously reported in the literature. pneumoniae, Rickettsia, HCV, HBV, Ebstein-Barre virus, poststreptococcal infection and coxsackie infection

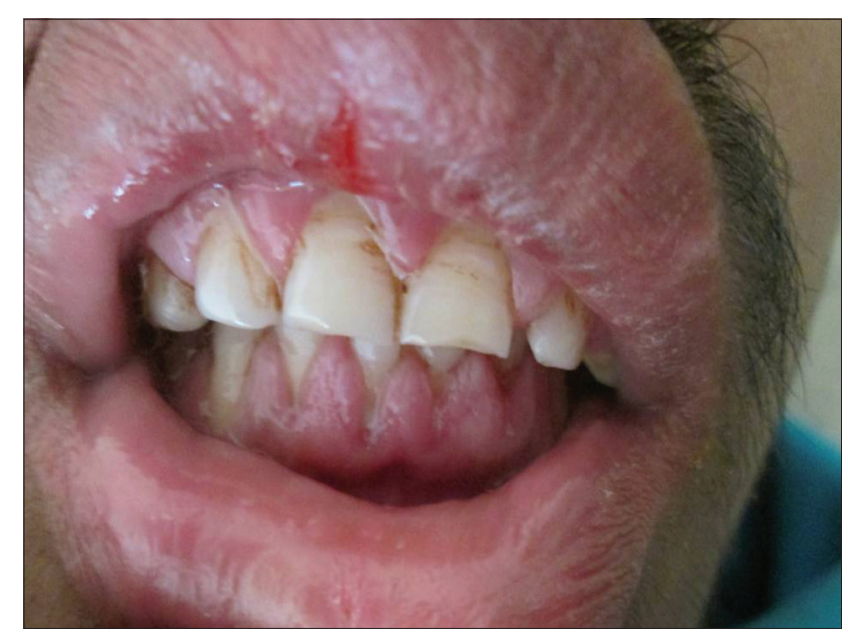

Figure 1: Photograph of the oral cavity showing gum hypertrophy 
was negative. Brain magnetic resonance imaging revealed no abnormality. Electroencephalography was normal. Ultrasonography of abdomen and chest X-ray was normal. Serum phenytoin level was markedly increased $(>40 \mu \mathrm{g} / \mathrm{ml})$. Phenytoin was stopped and levetiracetam $500 \mathrm{mg}$ bd and clonazepam $0.5 \mathrm{mg}$ tds was started. All his symptoms including opsoclonusmyoclonus were gradually disappeared over next 15 days. Therefore, phenytoin-induced opsoclonusmyoclonus ataxia syndrome was the final diagnosis. The repeat estimation of serum phenytoin level was within normal limits. The patient became seizure free at follow-up at 3 months.

Phenytoin side effects are ataxia, nystagmus, slurred speech, decreased coordination, dysarthria, diplopia, choreoathetosis, orofacial dyskinesias and mental confusion. ${ }^{[2]}$ Other uncommon side effects like ophthalmoplegia, seizure and encephalopathy (lethargy, delirium, psychosis, stupor or coma) may be seen, especially when serum phenytoin level $>40 \mu \mathrm{g} / \mathrm{ml} .^{[3]}$ Chronic use of phenytoin medication is associated with persistent cerebellar dysfunction and atrophy of cerebellar vermis along with loss of Purkinje cells. ${ }^{[4]}$

OMS is a rare neurological disorder and is also known as the "dancing eye-dancing feet syndrome." Opsoclonus is defined as the occurrence of involuntary, repetitive rapid conjugate ocular saccades that are irregular in amplitude and frequency, occur in all directions without an intersaccadic interval. Myoclonus occurs in most of OMS cases. OMS may be associated with ataxia, tremor, dysarthria and psychiatric symptoms.

OMS is more common in children. The most common cause of OMS in children is paraneoplastic, especially due to neuroblastoma, parainfectious and congenital. The exact pathophysiology of OMS is not known. Baets et al. ${ }^{[5]}$ had demonstrated loss of cerebellar purkinje and granular cell layer in autopsy of OMS of paraneoplastic origin.

Since OMS is a rare disease, so there are no guidelines regarding its management? In children with neuroblastoma, it usually resolves with adrenocorticotropic hormone (ACTH), or corticosteroid. There are reports in which clonazepam, baclofen, valproate had provided significant symptomatic relief to these patients. ${ }^{[6]}$

In our patient there was history of appearance of OMS after recent increment of dose of phenytoin and initially his symptoms were unresponsive to levetiracetam. There was significant response and complete resolution after withdrawal of phenytoin and addition of clonazepam with evidence of significant raised phenytoin level suggests that OMS was attributed to phenytoin toxicity. Although phenytoin and carbamazepine are known to aggravate myoclonic jerks in most of myoclonic epilepsies but phenytoin toxicity presenting as OMS had not reported till date.

Rajesh Verma, Sanjeev Kumar, Sumant Biyani, Anurag Singh

Department of Neurology, King George Medical University, Lucknow, Uttar Pradesh, India

Address for correspondence: Prof. Rajesh Verma, Department of Neurology, King George Medical University, Lucknow, Uttar Pradesh, India. E-mail: drrajeshverma32@yahoo.com

\section{References}

1. Dehaena I, Van Vleymen B. Opsoclonus induced by phenytoin and diazepam. Ann Neurol 1987;21:216.

2. Bruni J. Phenytoin: Toxicity. In: Levy RH, Mattson RH, Meldrum BS, editors: Antiepileptic Drugs. $4^{\text {th }}$ ed. New York: Raven Press; 1995. p. $345-50$.

3. Spector RH, Davidoff RA, Schwartzman RJ. Phenytoin-induced ophthalmoplegia. Neurology 1976;26:1031-4.

4. Ney GC, Lantos G, Barr WB, Schaul N. Cerebellar atrophy in patients with long-term phenytoin exposure and epilepsy. Arch Neurol 1994;51:767-71.

5. Baets J, Pals P, Bergmanse B, Foncke E, Smets K, Hauman H, et al. Opsoclonus-myoclonus syndrome: A clinicopathological confrontation. Acta Neurol Belg 2006;106:142-6.

6. Klaas JP, Ahlskog JE, Pittock SJ, Matsumoto JY, Aksamit AJ, Bartleson JD, et al. Adult-onset opsoclonus-myoclonus syndrome. Arch Neurol 2012;69:1598-607.

Video Available on: www.ruralneuropractice.com

\begin{tabular}{|l|l|}
\hline \multicolumn{2}{|c|}{ Access this article online } \\
\hline Quick Response Code: & Website: \\
\hline & www.ruralneuropractice.com \\
\cline { 2 - 2 } & \\
\hline & \\
\hline
\end{tabular}

